\title{
Effects of dexamethasone on immune dysfunction and ventilator-associated pneumonia in COVID-19 acute respiratory distress syndrome: an observational study
}

\author{
Martin Cour ${ }^{1,2^{*}}$ (D) Marie Simon ${ }^{1}$, Laurent Argaud ${ }^{1,2}$, Guillaume Monneret ${ }^{2,3}$ and Fabienne Venet ${ }^{2,3,4}$
}

\begin{abstract}
Dexamethasone improves survival of patients with COVID-19 acute respiratory distress syndrome, but might shorten the delay between the start of invasive mechanical ventilation and the occurrence of ventilator-associated pneumonia, suggesting possible worsening of COVID-19-induced immune dysfunction with this treatment. In a prospective observational study, we found that mechanically ventilated patients with COVID-19 treated with dexamethasone presented earlier ventilator-associated pneumonia, had significantly lower monocyte Human Leukocyte Antigen-DR expression and number of circulating CD4 + cells after ICU admission, than those not treated with corticoids.
\end{abstract}

Keywords: SARS-CoV-2, Monocyte HLA-DR, CD4 + lymphocyte, Nosocomial infection, Intensive care unit

Following the RECOVERY trial, dexamethasone became a standard treatment for most COVID-19 patients with acute respiratory distress syndrome (ARDS) [1]. Indeed, low dose of dexamethasone significantly decreased day28 mortality in COVID-19 ARDS [1]. This benefit is thought to be related to the anti-inflammatory properties of the drug. However, concerns raised about the risk of nosocomial infection [2]. A large multicentric observational study reported that ventilator-associated pneumoniae (VAP) occurred significantly earlier (but not more often) in patients treated with dexamethasone than in those who were not [3], suggesting a possible worsening of immune dysfunction with this drug. Nevertheless, the effects of dexamethasone on COVID-19-induced immune dysfunction remain undetermined. We, therefore, conducted a study to compare immune profiles of

\footnotetext{
*Correspondence: martin.cour@chu-lyon.fr

${ }^{1}$ Hospices Civils de Lyon, Intensive Care Medicine, Service de Médecine

Intensive-Réanimation, Hôpital Edouard Herriot, 5, Place d'Arsonval,

F-69437 Lyon Cedex 03, France

Full list of author information is available at the end of the article
}

COVID-19 patients admitted to intensive care unit (ICU) for ARDS and VAP characteristics before and after systematic use of dexamethasone.

This project was part of the prospective observational study REA-IMMUNO-COVID (RICO) that was approved by an institutional ethics committee ( ${ }^{\circ} I R B /$ IORG: \#IORG0009918) and registered (ClinicalTrials. gov: NCT04392401) [4].

Adult patients with COVID-19 ARDS (defined by Berlin criteria) hospitalized in a French academic ICU for $\geq 7$ days during the first wave (W1, march-April 2020) or the second wave (W2, October-November 2020) of the pandemic were screened and included if they (1) were included in RICO, (2) were not immunocompromised (i.e. no organ transplantation, HIV, cancer and/or chronic treatment with immunosuppressive drugs), and (3) had no missing data of interest. In addition, during W1, patients were excluded if they received corticoids before the first assessment of immune function. During W2, dexamethasone was given intravenously at a dose of $6 \mathrm{mg} /$ day for 10 days, as in RECOVERY [1] with no other original author(s) and the source, provide a link to the Creative Commons licence, and indicate if changes were made. The images or other third party material in this article are included in the article's Creative Commons licence, unless indicated otherwise in a credit line to the material. If material is not included in the article's Creative Commons licence and your intended use is not permitted by statutory regulation or exceeds the permitted use, you will need to obtain permission directly from the copyright holder. To view a copy of this licence, visit http://creativecommons.org/licenses/by/4.0/. The Creative Commons Public Domain Dedication waiver (http://creativeco mmons.org/publicdomain/zero/1.0/) applies to the data made available in this article, unless otherwise stated in a credit line to the data. 
significant therapeutic changes versus W1. VAP was defined according to international guidelines as a microbiologically confirmed pneumonia diagnosed after $48 \mathrm{~h}$ of intubation [5]. Monocyte Human Leukocyte AntigenDR (mHLA-DR) expression, absolute lymphocyte count and number of circulating CD4+cells were assessed within the first $48 \mathrm{~h}$ of ICU admission (D1), 72-96 h after admission (D3) and between days 7 and 9 (D7). We also recorded highest body temperatures of the day at D1, D3 and D7, as hyperthermia has been shown to be associated with mortality [6] and could be dampened by dexamethasone.

Among the 68 patients who were screened (W1: $n=31$; W2: $n=37), 36(53 \%)$ were included in the present study (W1: $n=18$; W2: $n=18$ ). The reasons for non-inclusion were: not being included in RICO $(n=24)$, immunocompromised status $(n=6)$ and missing data $(n=2)$. No patient received immunosuppressive drugs other than corticosteroids (e.g., tocilizumab) or remdesivir. Baseline patients' characteristics did not differ between the 2 waves (Table 1). During W2, in all patients but one, dexamethasone was started the day of ICU admission. The Sequential Organ Failure Assessment (SOFA) score at D1 was significantly higher in W1 versus W2 (Table 1). At D1, highest body temperature, mHLA-DR and CD4+lymphocytes, were significantly lower in patients treated with dexamethasone compared to those who were not (Fig. 1A, B and D). In both groups, median values of mHLA-DR (Fig. 1B) and lymphocyte counts (Fig. 1C and D) remained below normal values over 7 days. Afterwards, these differences faded. The proportion of patients who developed VAP was similar in the 2 groups. However, compared to W1, VAP occurred significantly earlier, duration of mechanical ventilation was significantly shorter and day-90 mortality lower during W2 (Table 1).

This study confirms the profound immunosuppression previously described in critically ill COVID-19 patients [4]. Compared to W1, a low dose of dexamethasone was associated with worsened immune dysfunction at D1 (as assessed by mHLA-DR and CD4+lymphocytes), earlier occurrence of VAP but also with prevention of fever and shorter duration of mechanical ventilation. The worsening of the immune dysfunction in patients from W2 could not be explained by baseline characteristics including organ dysfunctions as assessed by the SOFA score that were similar between the 2 groups.

Data on effects of corticoids on immune profile in critically ill patients remain scarce. In septic shock, low dose hydrocortisone was reported to slightly decrease

Table 1 Patients characteristics and outcomes

\begin{tabular}{|c|c|c|c|}
\hline & Wave $1(n=18)$ & Wave $2(n=18)$ & $P$ \\
\hline Age-years & $66[61-70]$ & $70[61-73]$ & 0.419 \\
\hline Male gender $-n(\%)$ & $14(78)$ & $15(83)$ & $>0.99$ \\
\hline Body mass index- $\mathrm{kg} / \mathrm{m}^{2}$ & $31[28-36]$ & $31[28-36]$ & 0.567 \\
\hline Hypertension-n (\%) & $8(44)$ & $10(56)$ & 0.740 \\
\hline Diabetes-n (\%) & $5(63)$ & $9(50)$ & 0.310 \\
\hline SAPS II score_-points & $39[33-50]$ & $37[31-47]$ & 0.486 \\
\hline SOFA score at Day $1^{\text {a }}$ - points & $8[6-9]$ & $5[2-8]$ & 0.041 \\
\hline Delay between symptoms and ICU admission—days & $6[4-9]$ & $9[7-11]$ & 0.09 \\
\hline Delay between ICU admission and intubation—days & $1[0-2]$ & $1[1,2]$ & 0.356 \\
\hline Bacterial superinfection at intubation $-n(\%)$ & $6(33)$ & $3(17)$ & 0.440 \\
\hline Lowest $\mathrm{PaO}_{2} / \mathrm{FiO}_{2}$ ratio during ICU stay $-\mathrm{mmHg}$ & $83[62-112]$ & $81[62-100]$ & 0.784 \\
\hline Severity of ARDS— $n(\%)$ & & & 0.460 \\
\hline Moderate & $6(33)$ & $4(22)$ & \\
\hline Severe & $12(67)$ & $14(78)$ & \\
\hline Duration of invasive mechanical ventilation-days & 29 [18-47] & 12 [8-22] & $<0.01$ \\
\hline Ventilation acquired pneumoniae $-n(\%)$ & $15(83)$ & $13(72)$ & 0.802 \\
\hline Delay between intubation and VAP_-days & $13[8-27]$ & $7[5-11]$ & 0.020 \\
\hline Day 28 mortality $-n(\%)$ & $5(28)$ & $2(11)$ & 0.210 \\
\hline Day 90 mortality—n (\%) & $8(44)$ & $3(17)$ & 0.150 \\
\hline
\end{tabular}

SAPS II Simplified Acute Physiology Score II, SOFA Sequential Organ Failure Assessment, ICU intensive care unit, ARDS acute respiratory distress syndrome, VAP ventilation acquired pneumoniae. Results were compared using Mann-Whitney test or Fisher's exact test, as appropriate

${ }^{a}$ Day 1: day of the first measures of lymphocytes counts and monocyte HLA-DR expression

Data are expressed as median (interquartile) and number (percentage) 

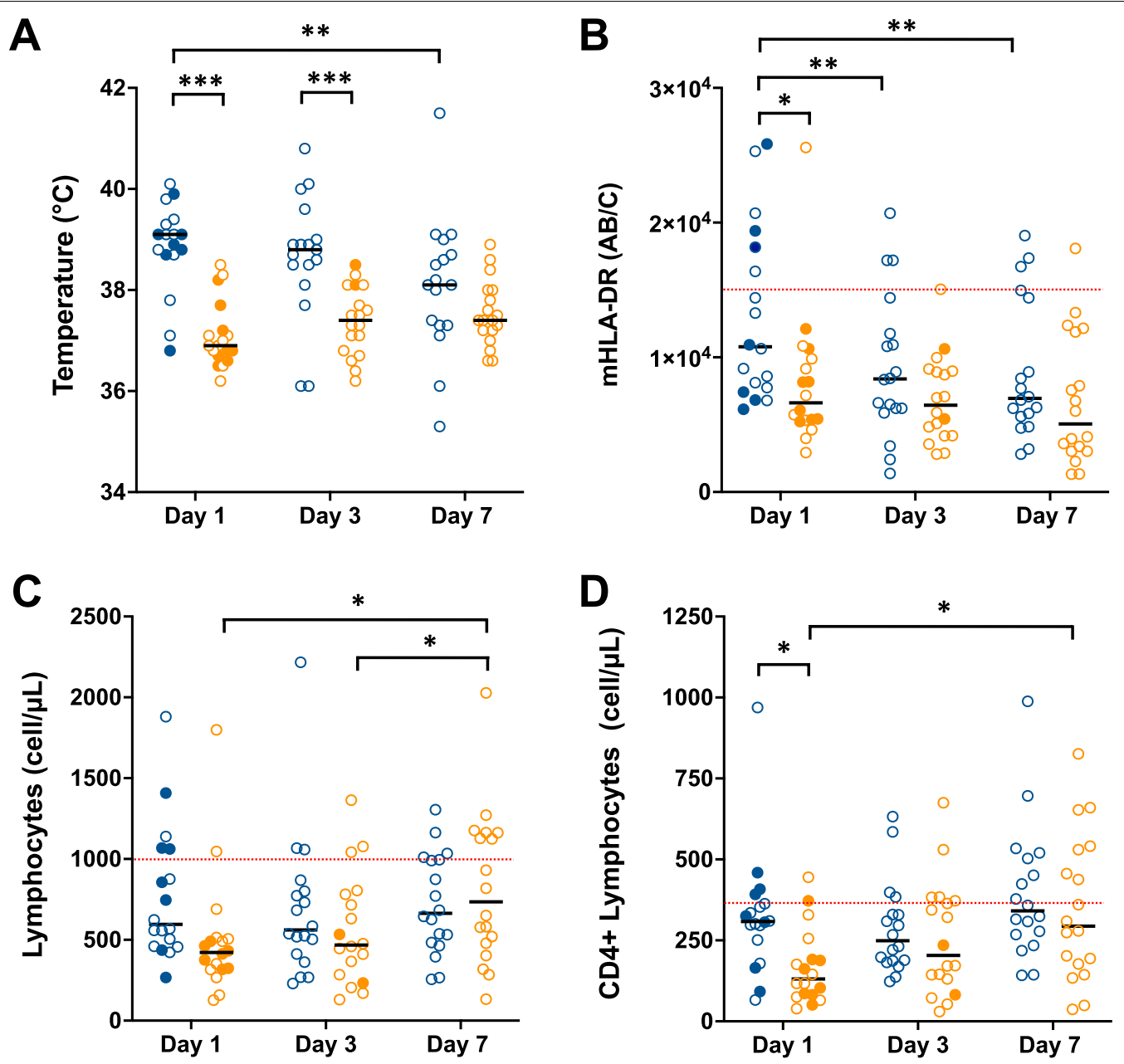

Fig. 1 Temperature, monocyte HLA-DR expression and lymphocytes count over time in COVID-19 patients with ARDS treated or not with dexamethasone. Individual (circles) and median (black hyphen) values of highest body temperature of the day (A), monocyte HLA-DR expression (mHLA-DR) expressed as numbers of antibodies bound per cells (AB/C), B), total lymphocytes count (C), and number of CD4+lymphocytes (D) are reported at day 1, 3, 7 after admission for 18 patients with COVID-19-induced with ARDS during the first wave of the pandemic (blue circle) who did not receive dexamethasone and for 18 patients of the second wave treated with dexamethasone (orange circle). Empty circles indicate patients receiving invasive mechanical ventilation and full circles patients not intubated. Red dashed line indicates lower normal values for mHLA-DR and lymphocytes counts. ${ }^{*} p<0.05 ;{ }^{* *} p<0.01 ;{ }^{* * *} p<0.001$ in two-way ANOVA with repeated measures

mHLA-DR while preventing release of pro-inflammatory cytokines [7]. In the present study, dexamethasone also dampened inflammation as shown by the dramatic decrease in fever observed during W2.

Even if incidence of VAP did not differ before and after systematic use of dexamethasone, this complication occurred significantly earlier during W2. A similar result was recently reported in a large multicentric observational study comparing VAP during W1 and W2 [3]. However, the association between early nosocomial infection and putative dexamethasone-induced immunodepression seems to be advantageously balanced by a shorter exposition to invasive devices in patients with COVID-19 ARDS. Despite a limited number of highly selected participants and possible changes in the management of patients over time that may limit generalizability, our results should alert physicians to the high rate of early VAP in COVID-19 ARDS patients treated with dexamethasone and to the necessity of a carefully immune monitoring of these patients.

\section{Abbreviations}

ARDS: Acute respiratory distress syndrome; ICU: Intensive care unit; mHLA-DR: Monocyte human leucocyte antigen-DR; VAP: Ventilator-associated pneumoniae; W1: Wave 1 of the COVID-19 pandemic; W2: Wave 2 of the COVID-19 pandemic. 


\section{Acknowledgements}

The authors would like to thank Marion Provent for essential assistance in initiating and conducting the study. The authors would also like to thank the Centre d'Investigation Clinique de Lyon (CIC 1407 Inserm) for great help in RICO clinical study management and patients and their families who agreed to participate to this clinical study.

\section{Authors' contributions}

MS and MC conceived and designed the study. MS and MC drafted the first version of the manuscript. MS, MC, LA, GM and FV collected the data. MS and $M C$ analyzed the data. LA, GM and FV critically revised the manuscript. All authors read and approved the final manuscript. All authors agree to be accountable for all aspects of the work. All authors read and approved the final manuscript.

\section{Funding}

This work was supported by funds from the Hospices Civils de Lyon, Fondation HCL and Claude Bernard Lyon 1 University/Région Auvergne Rhône-Alpes.

\section{Availability of data and materials}

All data generated or analyzed during this study are included in this published article (and its supplementary information files).

\section{Declarations}

\section{Ethics approval and consent to participate}

All procedures performed in studies involving human participants were in accordance with the ethical standards of our institutional research committee and with the 1964 Declaration of Helsinki and its later amendments. This project was part of an ongoing prospective observational clinical study (RICO, REA-IMMUNO-COVID). It was approved by ethics committee (Comité

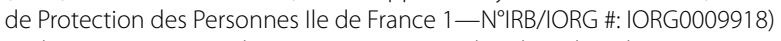
under agreement number 2020-A01079-30. This clinical study was registered at ClinicalTrials.gov (NCT04392401). The committee waived the need for written informed consent because the study was observational, with a low risk to patients, and no specific procedure, other than routine blood sampling, was required. Oral information and non-opposition to inclusion in the study were mandatory and were systematically obtained before any blood sample was drawn. This was recorded in patients' clinical files. If a patient was unable to consent directly, non-opposition was obtained from the patient's legally authorized representative and reconfirmed from the patient at the earliest opportunity.

\section{Consent for publication}

Not applicable.

\section{Competing interests}

The authors declare they have no competing interests.

\section{Author details}

${ }^{1}$ Hospices Civils de Lyon, Intensive Care Medicine, Service de Médecine Intensive-Réanimation, Hôpital Edouard Herriot, 5, Place d'Arsonval,
F-69437 Lyon Cedex 03, France. ${ }^{2}$ Faculté de médecine Lyon-Est, Université de Lyon, Université Claude Bernard Lyon 1, F-69437 Lyon, France. ${ }^{3}$ Immunology Laboratory, Hospices Civils de Lyon, Edouard Herriot Hospital, 69437 Lyon,

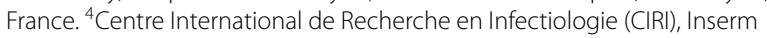
U1111, CNRS, UMR5308, Ecole Normale Supérieure de Lyon, Université Claude, Bernard-Lyon 1, Lyon, France.

Received: 29 September 2021 Accepted: 13 October 2021

Published online: 18 October 2021

\section{References}

1. RECOVERY Collaborative Group, Horby P, Lim WS, Emberson JR, Mafham M, Bell JL, et al. Dexamethasone in Hospitalized Patients with Covid-19. N Engl J Med. 2021;384:693-704. https://doi.org/10.1056/NEJMoa2021436.

2. Matthay MA, Thompson BT. Dexamethasone in hospitalised patients with COVID-19: addressing uncertainties. Lancet Respir Med. 2020;8:1170-2. https://doi.org/10.1016/S2213-2600(20)30503-8.

3. Gragueb-Chatti I, Lopez A, Hamidi D, Guervilly C, Loundou A, Daviet F, et al. Impact of dexamethasone on the incidence of ventilator-associated pneumonia and blood stream infections in COVID-19 patients requiring invasive mechanical ventilation: a multicenter retrospective study. Ann Intensive Care. 2021:11:87. https://doi.org/10.1186/s13613-021-00876-8.

4. Venet F, Cour M, Rimmelé T, Viel S, Yonis H, Coudereau R, et al. Longitudinal assessment of IFN-I activity and immune profile in critically ill COVID-19 patients with acute respiratory distress syndrome. Crit Care. 2021;25:140. https://doi.org/10.1186/s13054-021-03558-w.

5. Kalil AC, Metersky ML, Klompas M, Muscedere J, Sweeney DA, Palmer $L B$, et al. Management of adults with hospital-acquired and ventilatorassociated pneumonia: 2016 Clinical Practice Guidelines by the Infectious Diseases Society of America and the American Thoracic Society. Clin Infect Dis. 2016;63:e61-111. https://doi.org/10.1093/cid/ciw353.

6. Tharakan S, Nomoto K, Miyashita S, Ishikawa K. Body temperature correlates with mortality in COVID-19 patients. Crit Care. 2020;24:298. https:// doi.org/10.1186/s13054-020-03045-8.

7. Keh D, Boehnke T, Weber-Cartens S, Schulz C, Ahlers O, Bercker S, et al. Immunologic and hemodynamic effects of "low-dose" hydrocortisone in septic shock: a double-blind, randomized, placebo-controlled, crossover study. Am J Respir Crit Care Med. 2003;167:512-20. https://doi.org/10. 1164/rccm.200205-4460C.

\section{Publisher's Note}

Springer Nature remains neutral with regard to jurisdictional claims in published maps and institutional affiliations.

\footnotetext{
Ready to submit your research? Choose BMC and benefit from:

- fast, convenient online submission

- thorough peer review by experienced researchers in your field

- rapid publication on acceptance

- support for research data, including large and complex data types

- gold Open Access which fosters wider collaboration and increased citations

- maximum visibility for your research: over $100 \mathrm{M}$ website views per year
}

At BMC, research is always in progress.

Learn more biomedcentral.com/submissions 